\title{
Penanganan Anak Korban Kekerasan dengan Menggunakan Metode Ecobehavior
}

\author{
Gagas Dio Agil Liyanto, dan Nur Endah Nuffida \\ (ITS) \\ Jl. Arief Rahman Hakim, Surabaya 60111 \\ E-mail:nuffida@arch.its.ac.id
}

Jurusan Arsitektur, Fakultas Teknik Sipil dan Perencanaan, Institut Teknologi Sepuluh Nopember

\begin{abstract}
Abstrak-Anak yang mengalami kekerasan akan mengalami dampak dengan gejala berbagai macam dan berbeda-beda tergantung kejadian yang dialami korban. Namun pada umumnya akan memiliki dampak seperti mudah marah, tempramental, stres yang dilampiaskan ke tindakan kasar, trauma, merasa cemas yang berkelanjutan, depresi, pendiam, sensitif, cenderung menarik diri kehidupan sosial, bahkan yang paling parah adanya kecenderungan untuk melakukan bunuh diri karena tidak sanggup menananggung peristiwa yang dialaminya. Perlu adanya penanganan fasilitas yang dapat mendukung proses terapi dan memperbaiki perilaku anak. Dan juga dapat mempersiapkan anak untuk kembali ke lingkungan sosial mereka seperti semula. Objek rancang yang mewadahi respon tersebut adalah Fasilitas Rehabilitasi Anak Korban Kekerasan yang menggunakan metode ecobehavior sebagai penananganannya. Dengan menerapkan metode desain Rationalist Approaches, serta pendekatan Behavior Setting dan Architecture for Children, metode ecobehavior tersebut dapat dihadirkan kedalam fasilitas yang memiliki elemen-elemen arsitektur menyesuaikan kebutuhan dari pengguna.
\end{abstract}

Kata Kunci- Kekerasan, Anak, Ecobehavior, Perilaku, Arsitektur.

\section{PENDAHULUAN}

$\mathrm{K}$ EKERASAN terhadap anak dapat terjadi di lingkungan tempat tinggal, sekolah maupun di lingkungan keluarga sendiri. Kekerasan memiliki dampak seperti trauma, merasa cemas yang berkelanjutan, depresi, gangguan pengendalian diri, cenderung menarik diri kehidupan sosial bahkan yang paling parah adanya kecenderungan untuk melakukan bunuh diri karena tidak sanggup menanggung peristiwa yang dialaminya. Dampak dari kekerasan juga dapat memunculkan pelaku-pelaku kekerasan baru yang berasal dari korban. Menurut KPAI anak tidak hanya menjadi korban tetapi juga sebagai pelaku, hal ini yang menyebabkan kasus kekerasan di Indonesia meningkat tiap tahunnya [1]. Sedangkan proses penanganan tindak rehabilitasi masih terganggu karena suasana pada fasilitas yang kurang mendukung proses terapi, dan masih belum dapat mempersiapkan anak untuk kembali ke lingkungan sosial mereka seperti semula.

Maka untuk merespon keadaan tersebut perlu adanya fasilitas yang dapat mendukung proses terapi untuk anak korban kekerasan, yang dapat mengarahkan perilaku dan kondisi psikis anak menjadi lebih baik. Fasilitas tersebut memiliki lingkungan yang dapat membantu anak korban kekerasan agar dapat bersosialisasi kembali ke dalam lingkungan sosial mereka seperti semula. Dengan menerapkan metode penyembuhan ecobehavior kedalam suatu objek rancang fasilitas rehabilitasi anak korban kekerasan respon tersebut dapat dihadirkan melalui karakter
Tabel 1. Data Kekerasan Anak

\begin{tabular}{lc}
\hline Tahun & Jumlah Kasus \\
\hline 2011 & 2179 \\
2012 & 3512 \\
2013 & 4311 \\
2014 & 5066 \\
2015 & 6006 \\
\hline & Sumber: kpai.go.id
\end{tabular}

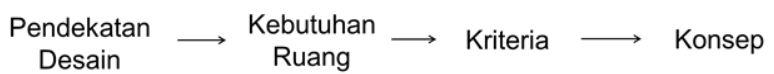

Gambar 1 Metode Desain
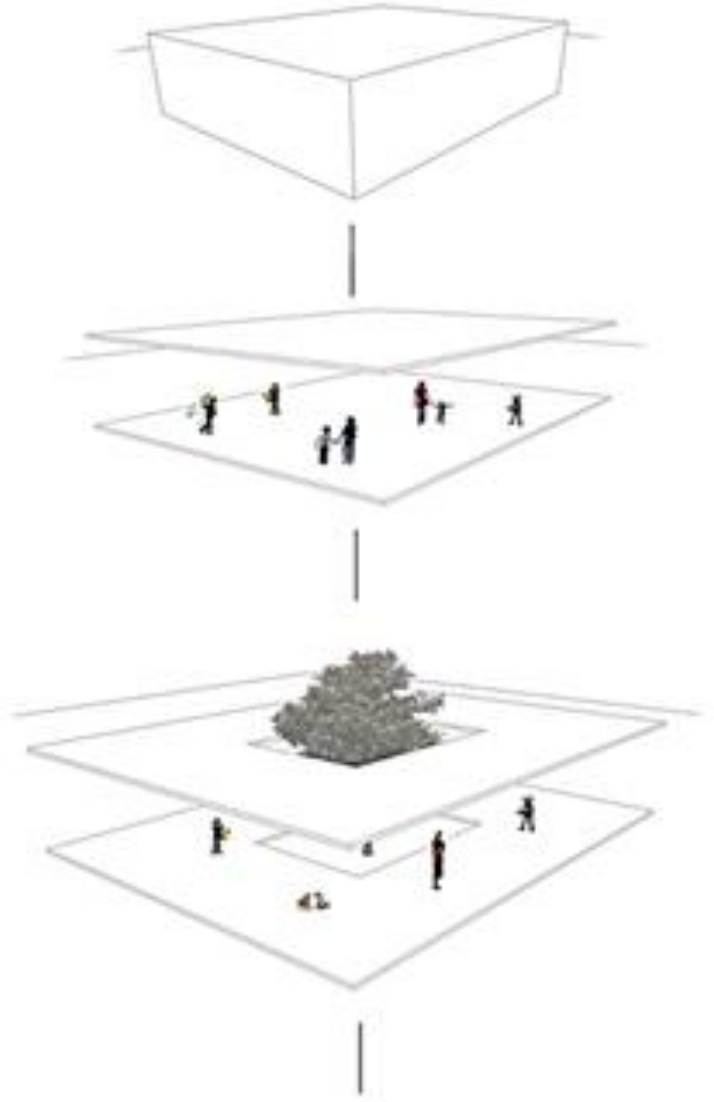

Gambar 2 Ekplorasi bentuk (a). 
ruang, suasana, konsep tatanan dan elemen-elemen arsitektur. Metode tersebut merupakan proses terapi yang menghadirkan lingkungansosial anak dan orang tua atau keluarga korban dengan aktivitas pelatihan, keterampilan, kegiatan sosialisasi dan aktivitas yang menenangkan yang dapat memperbaiki perilaku dan kondisi anak menjadi lebih baik. Dengan suasana lingkungan yang natural atau dekat dengan alam dan menyenangkan. Karena alam dapat membuat kondisi psikologis menjadi lebih tenang dan stabil [2].

\section{EKSPLORASI DAN PROSES RANCANG}

Menurut Kari Jormakka dalam Basics Design Methods (2008), terdapat beberapa klasifikasi metoda desain. Metoda yang dipilih dalam proses perancangan ini adalah Rationalist Approaches. Dalam pendekatan rasional, arsitektur membutuhkan adanya pengetahuan dasar di berbagai bidang di luar arsitektur [3]. Permasalahan pada objek ini berkaitan dengan psikologis anak. Pendekatan ekstrinsik maupun intrinsik berkaitan dengan psikologis dan perilaku anak digunakan untuk eksplorasi rancang.

Pendekatan yang digunakan adalah behavior setting, dimana pola perilaku, aktivitas dan karakter lingkungan diperhatikan. behavior setting dapat terbentuk dari rangkaian perilaku, aktivitas, persepsi, motivasi (dorongan yang ada dibalik perilaku), serta faktor-faktor lingkungan. Dengan setting perilaku yang dihadirkan adalah metode penanganan ecobehavior [4]. Untuk mendukung pendekatan dan juga konteks yang dibicarakan tentang anak, maka diperlukan pendekatan architecture for children. Menurut Sarah scott (2010) dalam architecture for children, Setiap elemen arsitektur dalam fasilitas anak-anak harus dirancang sesuai dengan dunia mereka baik itu warna, skala, jarak dari tata letak ruang, semua disesuaikan dengan anak-anak. Dengan menghadirkan area ruang luar untuk bermain dan saling berinteraksi menjadi salah satu poin penting, karena anakanak akan merasa lebih bebas dan tidak terkurung oleh ruang. Transparasi, ini juga menjadi bagian penting dalam rancangan fasilitas anak-anak. Dengan ruang-ruang transparan dimana anak dapat melihat anggota keluarga yang dikenali saat beraktivitas lebih aman dan tenang [5]. Dari pendekatan tersebut dapat diterapkan dengan konsep memasukan unsur alam dan transparansi tiap ruang, diamana anak, orang tua dan terapis dapat berkativitas bersama dengan nuansa alam yang menangkan. Dengan begitu aktivitasaktivitas penanganan dapat terdukung melalui ruang, suasana dan lingkungan.

\section{HASIL RANCANGAN}

\section{A. Konsep Tapak dan Exterior}

Tatanan tapak berdasarkan kebutuhan ruang dan aktivitasaktivitas terapi, dibedakan antara area terapi dan area rawat inap. Tatanan didapatkan dari karakteristik anak yang ketika bermain selalu mengitari area bermainnya, maka tatanan ruang area terapi dirancang mengitari dan saling terhubung agar aktivitas dari setiap terapi saling berdekatan, dan anakanak bisa saling melihat dan mengetahui aktivitas teman lainnya tanpa ada rasa khawatir. Sehingga kedekatan anakanak dan orang tua atau keluarga korban yang beraktivitas bersama semakin tinggi.
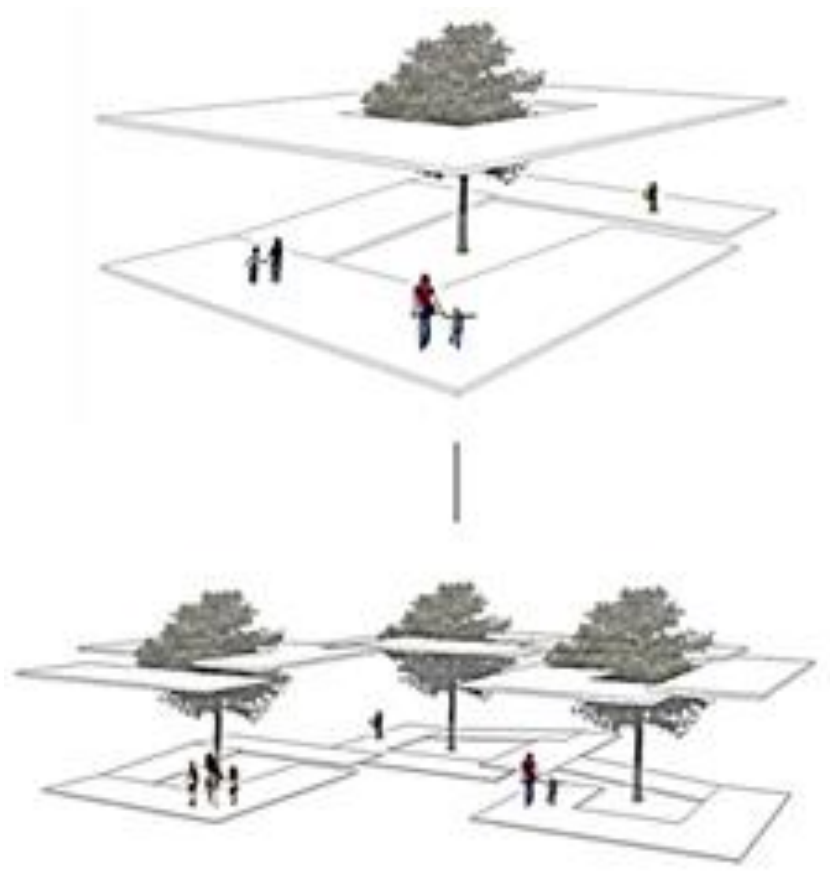

Gambar 2 Eksplorasi bentuk (b)

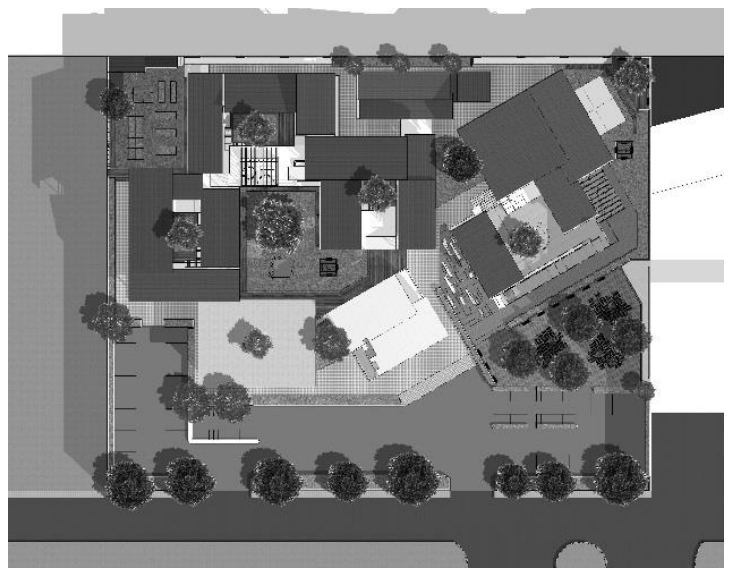

Gambar 3. Siteplan

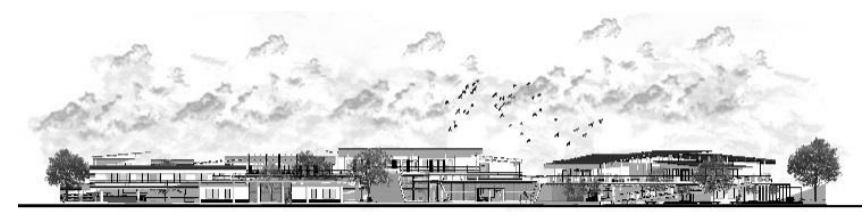

Gambar 4. Tampak Site Utara

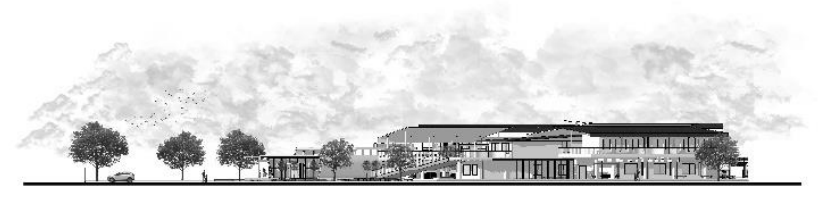

Gambar 5. Tampak Site Timur 
Untuk gubahan massa berawal dari pendekatan yang digunakan, yakni memasukan unsur ruang luar ke dalam ruang dalam dan menggunakan transparansi pada area aktivitas terapi sehingga tanpa ada batasan dinding. Dan untuk wajah atau tampilan sendiri menggunakan warna putih dan tidak terlalu mencolok, ini agar memberikan kesan yang tenang, aman, dan bersih bagi anak-anak yang memiliki kondisi psikologis yang kurang stabil. Dengan memberikan kesan yang tenang dan aman, anak tidak merasa takut dan tertekan ketika pertama kali datang.

\section{B. Konsep Ruang Interior}

Konsep ruang pada aktivitas terapi dihadirkan tanpa ada batasan dinding dengan ruang luar dengan nuansa natural dan alamiah. Dengan memasukan unsur ruang luar kedalam ruang dalam, dapat membuat psikologis anak ketika melakukan aktivitas terapi anak menjadi lebih tenang. Dan tentunya mengacu pada pendekatan architecture for children, dapat menhadirkan area bermain yang memiliki skala, batas dan elemen-elemen arsitektur yang dapat menjadi area bermain. Transparansi ruang pada aktivitas terapi dapat menghubungkan antara anak-anak yang melakukan aktivitas didalam dengan diluar.

\section{Konsep Ruang Luar}

Untuk ruang luar dihadirkan dengan nuansa berbeda-beda sesuai fungsi dan penggunanya. tempat untuk bermain bersama, untuk orang tua atau keluarga duduk bersantai bersosialisasai sesama anggota keluarga korban lainnya, ada yang dijadikan tempat beristirahat sejenak perawat, terapis dan pegawai, ada juga digunakan untuk tempat menyendiri bagi anak yang masih membutuhkan masa penyesuaian. Penggunaan unsur-unsur alam menjadi bagian penting, karena dapat menenangkan dan mendukung suasana kebersamaan. Seperti menghadirkan pepohonan yang rindang sebagai peneduh, suara aliran air yang berasal dari tirai air buatan. Konsep ruang luar juga memeperhatikan bagaimana karakter dan suasana dapat menyembuhkan kondisi psikologis pengguna sehingga menjadi lebih tenang. Ruang Luar dihadirkan berbeda-beda sesuai fungsi dan pengguna, ada yang digunakan kelompok-kelompok kecil ada juga yang digunakan untuk kelompok besar, sehingga memiliki luasan yang berbeda-beda sesuai jenis aktivitas yang dilakukan.

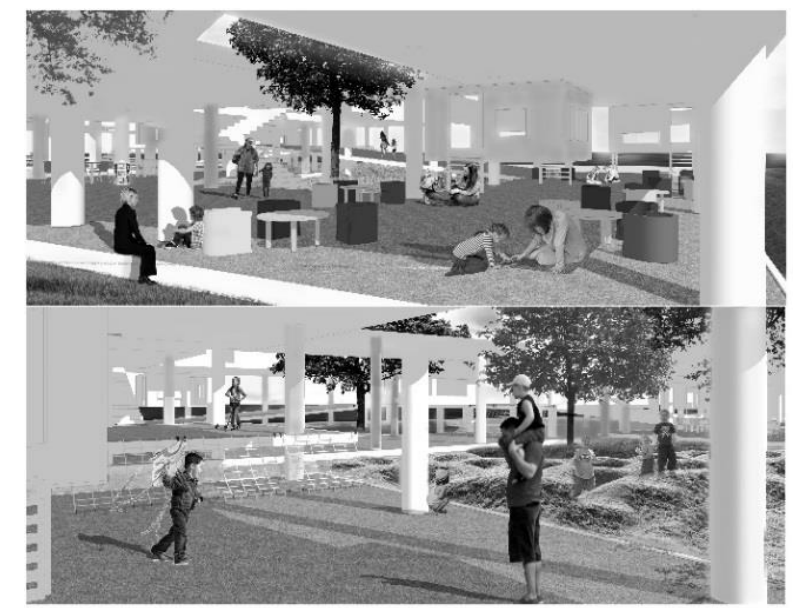

Gambar 6. Interior area bermain dan terapi

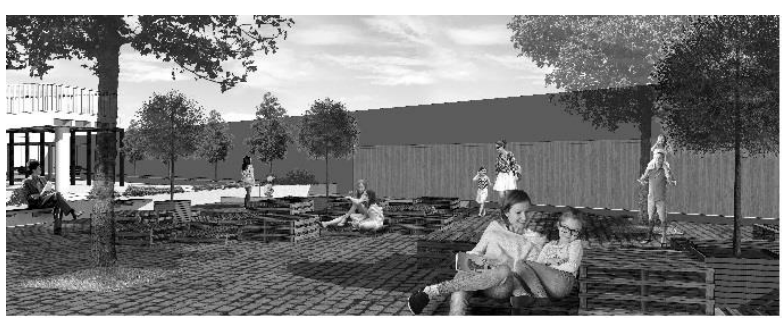

Gambar 7. Taman untuk Kunjungan Keluarga

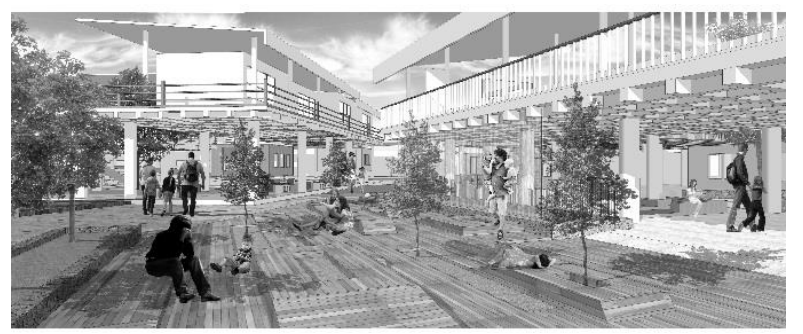

Gambar 8. Taman Kayu

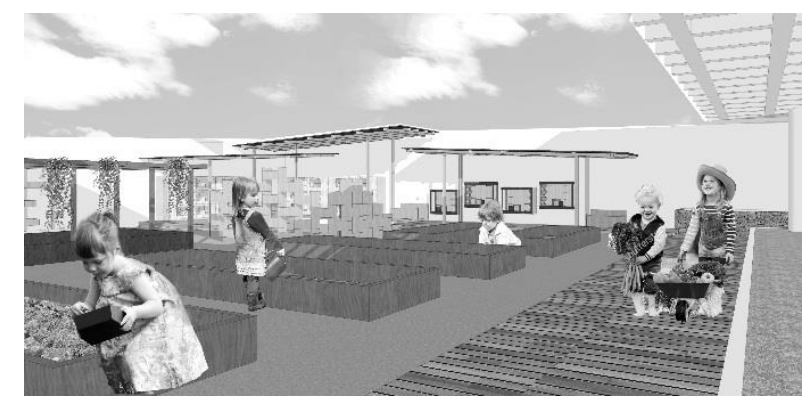

Gambar 9. Kebun

\section{KESIMPULAN}

Metode Ecobehavior dapat diterapkan kedalam arsitektur melalui karakter ruang, suasana dan bentuk dalam objek rancang fasilitas rehabilitasi anak korban kekerasan. Melalui pendekatan behavior setting dan architecture for children, penanganan anak korban kekerasan dengan metode ecobehavior dapat hadir dan mendukung proses terapi dan penanganan. Dengan menghadirkan alam sebagai media pendukung suasana dan ruang untuk aktivitas pelaku, kondisi psikologis dan perilku pengguna dapat menjadi lebih baik. Sehingga dengan adanya lingkungan sosial yang mendukung dalam sebuah fasilitas rehabilitasi anak korban kekerasan, dapat mempersiapkan anak untuk kembali ke lingkungannya seperti semula.

\section{DAFTAR PUSTAKA}

[1] Setiawan, Davit. 2015 . KPAI: Pelaku Kekerasan Terhadap Anak Tiap Tahun Meningkat [Online], (http://www.kpai.go.id/berita/kpai-pelakukekerasan-terhadap-anak-tiap-tahun-meningkat/,diakses tanggal 15 Agustus 2016).

[2] Lutzker, John R. (1997), Handbook of Child Abuse Research and Treatment, University of Judaism; Los Angeles.

[3] Jormakka, Kari. (2008), Basics Design Method, Birkhäuser.

[4] Laurens, J. Marcella (2004), Arsitektur dan Perilaku Manusia, Jakarta.

[5] Scott, Sarah (2010), Architecture for Children, Australia. 